\title{
3 Research Square

\section{Remotely Sensed Estimation of Total Iron Content in Soil With Harmonic Analysis and BP Neural Network}

\section{xueqin jiang}

School of Remote sensing Information Engineering

\section{Shanjun Luo}

Wuhan University

Shenghui Fang ( $\square$ Shenghfang@whu.edu.cn)

School of Remote Sensing and Information Engineering, Wuhan University, Wuhan, 430079, Chi-na https://orcid.org/0000-0002-7066-3243

\section{Bowen Cai}

Wuhan University

\section{Qiang Xiong}

Wuhan University

\section{Yanyan Wang}

Wuhan University

\section{Xia Huang}

Wuhan University

Xiaojuan Liu

Wuhan University

\section{Research}

Keywords: total iron content, harmonic analysis, wavelet packet transform, principal component analysis, BP neural network

Posted Date: April 30th, 2021

DOl: https://doi.org/10.21203/rs.3.rs-452299/v1

License: (a) (i) This work is licensed under a Creative Commons Attribution 4.0 International License. Read Full License

Version of Record: A version of this preprint was published at Plant Methods on November 12th, 2021. See the published version at https://doi.org/10.1186/s13007-021-00812-8. 


\section{Remotely sensed estimation of total iron content in}

\section{soil with harmonic analysis and BP neural network}

Xueqin Jiang ${ }^{1, \dagger}$, Shanjun Luo ${ }^{1, \dagger}$, Shenghui Fang ${ }^{1,2, *}$, Bowen Cai ${ }^{1}$, Qiang Xiong ${ }^{1}$, Yanyan Wang 3

${ }^{1}$, Xia Huang ${ }^{1}$, Xiaojuan Liu ${ }^{1}$

* Correspondence: shfang@whu.edu.cn $\quad 5$

1 School of Remote Sensing and Information Engineering, Wuhan University, Wuhan, 430079, China; 6

2 Lab of Remote Sensing for Precision Phenomics of Hybrid Rice, Wuhan University, Wuhan 430079, 7

$\begin{array}{ll}\text { China } & 8\end{array}$

$\dagger$ These authors contributed equally to this work. $\quad 9$

Abstract

Background: The estimation of total iron content at the regional scale is much of significance as iron 12

$\begin{array}{ll}\text { deficiency has become a routine problem for many crops. } & 13\end{array}$

Methods: In this study, a novel method for estimating total iron content in soil (TICS) was proposed 14

using harmonic analysis (HA) and back propagation (BP) neural network model. Several data prepro- 15

cessing methods of first derivative (FD), wavelet packet transform (WPT), and HA were conducted to 16

improve the correlation between the soil spectra and TICS. The principal component analysis (PCA) was 17

exploited to obtained three kinds of characteristic variables (FD-PCA, WPT-FD-PCA, and WPT-FD- 18

HA-PCA) for TICS estimation. Furthermore, the estimated accuracy of three BP models based on these 19

$\begin{array}{lr}\text { variables was compared. } & 20\end{array}$

Results: The results showed that the BP models of different soil types based on WPT-FD-HA-PCA had 21 better estimation accuracy, with the highest $\mathrm{R}^{2}$ value of 0.95 , and the RMSE of 0.68 of the loessial soil. 22 It was proved that the characteristic variable obtained by harmonic decomposition improved the validity 23 of the input variables and the estimation accuracy of the TICS models. Meanwhile, it was identified that 24 the WPT-FD-HA-PCA-BP model can not only estimate the total iron content of a single soil type with 25 high accuracy but also demonstrate a good effect on the estimation of TICS of mixed soil. 26 
Conclusion: The HA method and BP neural network combined with WPT and FD have great potential

in TICS estimation under the conditions of single soil and mixed soil. This method can be expected to

Keywords: total iron content, harmonic analysis, wavelet packet transform, principal component analy-

\section{Background}

Iron is an indispensable trace element for plants, whose content in soils largely relies on the $\mathrm{pH}$ value and the water content, and is influenced by root respiration, soil microbial activity, leaching, and erosion [1]. Accurate estimation of the total iron content in soil (TICS) is helpful for agronomists to adjust soil conditions, which is also the key to ensure the healthy growth of crops. Therefore, rapid and precise prediction of TICS has important practical value for precision agriculture [2,3].

The traditional determination methods of TICS include the combination of field sampling and laboratory measurement, assisted by atomic absorption spectrometry [4] and o-phenanthroline colorimetry [5]. Although a high accuracy was obtained, these methods were time-consuming and costly on a largearea application. In recent years, hyperspectral remote sensing (HRS) technology has the advantages of high resolution, fast speed, and high accuracy, which makes it possible to estimate the TICS in a large area quickly and efficiently [6]. HRS is one of the frontier remote sensing technologies since it provides continuous spectral information about each feature of the research object [7]. Several scholars have used HRS to predict nitrogen content [8], water content [9], and heavy metal content in soils [10]. They found that spectral preprocessing plays an important role in quantitative inversion and estimation.

At present, the TICS retrieving accuracy of HRS is limited by using traditional preprocessing methods due to the low iron contents and various existing forms in soils. For example, Bendor and Banin established a multiple linear regression model to predict the TICS by using 1075, 1025, and $425 \mathrm{~nm}$ spectral bands, with the highest $R^{2}$ of 0.76 [11]. Subsequently, a large number of researchers applied first and second derivative [12], reciprocal and logarithm [13], continuum removal methods [14] to expand spectral differences and reduce noise interference, thereby increasing the correlation between spectral data and TICS. This can be seen in the case that Guo et al. analyzed the correlation between different 
spectral forms and the content of iron oxide in soil by different spectral transformations, and the highest inversion accuracy was 0.93 [15].

The characteristic bands were used to serve as the characteristic variables in many studies. How-

ever, the soil spectral curve is a comprehensive manifestation of the interaction and superposition of various substances, thus the determination of the characteristic bands is not only difficult but also highly uncertain. Due to the complexity of soil compositions, the interference of other components will lead to the signal-to-noise ratio reduced under the conditions of low TICS in soils. Therefore, the selection of appropriate spectral denoising methods (such as wavelet transform, filtering, and average weighting) is of great importance. The wavelet transform has a strong ability to remove noise [16]. When it was applied to soil spectral data analysis, the spectral signal can be decomposed into sub-signals with different frequencies. It can effectively use the overall structural characteristics of spectral information, extract the weak information hidden in the spectral signal, and search for the best combination of sub-signal components to estimate the TICS. Gu et al. found that soil organic matter content can be retrieved using the high-frequency coefficients created with the wavelet transform and random forest algorithm [17].

Harmonic analysis (HA) was proposed to transform the time domain of the preprocessed spectral data into the frequency domain [18]. Harmonic decomposition can suppress or eliminate the background noise of ground objects and achieve the effect of data compression. The best harmonic component obtained by harmonic decomposition can be used as the characteristic variable to construct the inversion model of TICS. The inversion accuracy of TICS depends on the selection of the inversion model and characteristic variables. Quantities of studies have shown that the statistical analysis methods can be applied to the hyperspectral inversion of TICS, and the back propagation (BP) neural network can deal with the nonlinear situation well in the estimation of TICS as a result of its strong self-learning ability [19]. As the significant differences in physical and chemical properties of different types of soils, the study of soil spectral characteristics is relatively complex. Therefore, it is meaningful to carry out the estimation of total iron content in different types of soils.

In this paper, the hyperspectra of different types of soils were remotely measured from ground were employed for dimensionality reduction and feature variable extraction. Then the BP neural network 
improvement of the retrieving accuracy of TICS by the characteristic variables derived from HA, and (3) to apply the characteristic variables obtained by HA to three different types of soil to explore the optimal characteristic variables for TICS estimation of different soil types.

\subsection{Study Area}

The field sampling experiments were conducted in Hengshan County, Shaanxi Province, China $\left(37^{\circ} 22^{\prime} \mathrm{N}-38^{\circ} 14^{\prime} \mathrm{N}, 108^{\circ} 65^{\prime} \mathrm{E}-110^{\circ} 02^{\prime} \mathrm{E}\right)$, which belongs to the hilly and gully region of the Loess Plateau in the upper and middle reaches of the Yellow River with a total area of $4333 \mathrm{~km}^{2}$. Hengshan County was seriously affected by desertification due to the proximity to the Mu Us Desert. It belongs to the semidry continental monsoon climate, with an annual average temperature of $8.6^{\circ} \mathrm{C}$ and average annual precipitation of $399 \mathrm{~mm}$. The soil of this area is mainly composed of loessial soil and sandy soil. The difference in TICS was caused by the above comprehensive factors. The study area (Fig. 1) is conducive to estimating TICS in the districts with rich soil types. Taking Hengshan County as the study area, the occasionality and limitation caught by a single soil type can be avoided, which makes the research results more popularized and adaptable.

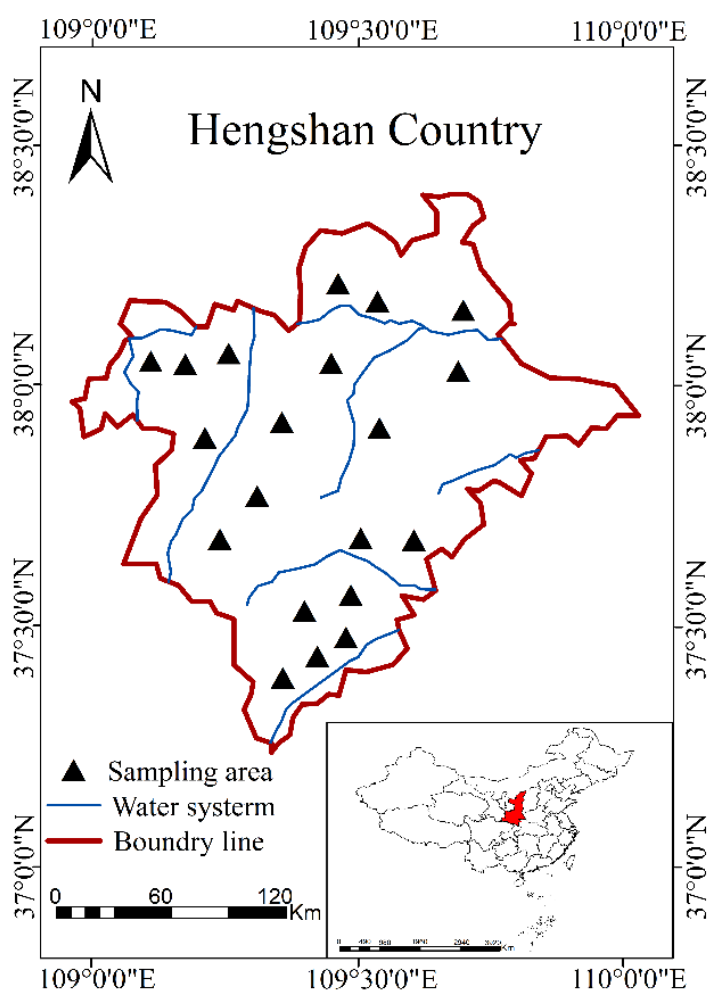

Fig.1 Study area location and sampling points distribution. 
The soil sampling of TICS was performed in the flat terrain and bare soil areas. Two types of soil (loessial soil and sandy soil) were collected and four or five representative survey points in each sampling area were selected. At each sampling point, a sample of surface soil (about $5 \mathrm{~cm}$ ) was dug up and put into a plastic bag. A total of 84 soil surface samples were collected, including 51 loessial soil samples and 33 sandy soil samples (Figure 1 and Table 1). All the collected samples were encapsulated and sent

Table 1. Descriptive statistics of total iron content in soil.

\begin{tabular}{ccccccc}
\hline \multirow{2}{*}{ Soil types } & \multirow{2}{*}{ Samples } & \multicolumn{7}{c}{ TICS (g/kg) } \\
\cline { 2 - 7 } & Min & Max & Mean & SD & CV \\
\hline Loessial & 51 & 15.42 & 27.51 & 23.26 & 2.28 & $9.82 \%$ \\
$\quad$ soil & & & & & \\
Sandy soil & 33 & 7.20 & 27.18 & 19.20 & 4.60 & $23.98 \%$ \\
Mixed soil & 84 & 7.20 & 27.51 & 21.66 & 3.93 & $18.13 \%$ \\
\hline
\end{tabular}

\subsection{Measurements of Soil Spectral Reflectance}

The soils were grinded and then screened by a $2 \mathrm{~mm}$ diameter sieve to obtain the samples for measuring spectral reflectance. The spectral reflectance measurements of the preprocessed soil samples were to $2500 \mathrm{~nm}$ with the spectral resolution of $3 \mathrm{~nm}$ during the range of 350 to $1000 \mathrm{~nm}$ and $10 \mathrm{~nm}$ during the range of 1000 to $2500 \mathrm{~nm}$. A $50 \mathrm{~W}$ halogen lamp (0.5 m from the soil samples) was used as the only mately $0.2 \mathrm{~m}$. A whiteboard (chemical composition: $\mathrm{BaSO}_{4}$ ) was used for relative radiometric correction. 117 Four spectra were averaged into a single one for each soil sample to decrease the instability of the meas- 118 urements.

\subsection{Data Processing and Analysis}

\subsubsection{Five-point Weighted Average}

The five-point weighted average method was applied to eliminate random errors. The window with five spectral data points was moved in the spectral data of each sample, and the values of the middle data 
gradually with the increase of the distance from the middle point, and the value of the middle point of

$$
\mathrm{S}=\left(\mathrm{S}_{\mathrm{n}-2} / 4+\mathrm{S}_{\mathrm{n}-1} / 2+\mathrm{S}_{\mathrm{n}}+\mathrm{S}_{\mathrm{n}+1} / 2+\mathrm{S}_{\mathrm{n}+2} / 4\right) / 2.5
$$

Where the $\mathrm{S}$ is the five-point weighted average value of the spectral data. Among the five spectral data, 128 $\mathrm{S}_{\mathrm{n}-2}, \mathrm{~S}_{\mathrm{n}-1}, \mathrm{~S}_{\mathrm{n}+1}, \mathrm{~S}_{\mathrm{n}+2}$ are the first, second, fourth, and fifth spectral data, respectively.

\subsubsection{First Derivative of Spectra}

The first derivative (FD) was performed after a five-point weighted average operation to eliminate

$$
R^{\prime}\left(\lambda_{i}\right)=\left[R\left(\lambda_{i+1}\right)-R\left(\lambda_{i-1}\right)\right] /\left(\lambda_{i+1}-\lambda_{i-1}\right)
$$

Where $\mathrm{R}^{\prime}\left(\lambda_{\mathrm{i}}\right)$ represents the FD spectral reflectance of wavelength $\lambda_{\mathrm{i}}$. R is the original spectral reflectance. 134

\subsubsection{Wavelet Packet Transform}

Wavelet packet transform (WPT) was utilized to precisely decompose and reconstruct high-frequency information (HFI), and to remove the noise of HFI as well. WPT based on the wavelet transform is superior to the wavelet transform in decomposing and reconstructing HFI [21,22]. The results of information processing do not exit redundancy and omission, so it is more conducive to spectral denoising and original information preservation. In this study, we decomposed and reconstructed the spectral data according to the four steps: (1) wavelet packet analysis of spectra using Db10 as wavelet generating wavelet packet basis of WPT decomposition according to the principle of minimum cost. (3) quantifying WPT spectral information based on the optimal wavelet packet basis and the quantitative optimal wavelet packet decomposition coefficients to obtain the spectra of WPT noise reduction. Finally, WPT spectra

\subsubsection{Harmonic Analysis}

Abundant issues of noise and redundancy still existed after the above operations. Harmonic analysis 
posed into a series of harmonic energy characteristic parameters by harmonic decomposition. The harmonic theory was used to express a time-series function $\mathrm{f}(\mathrm{t})$ in the form of sine or cosine wave (harmonic) 154 superposition. Namely, any time-series $\mathrm{f}(\mathrm{t})$ about time $\mathrm{t}$ can be expressed by several sine or cosine wave 155 superposition. The hyperspectral reflectance of each soil sample can be served as a continuous function 156 (during the range of wavelength). When using HA to process spectral data, the spectral curve composed 157 of $\mathrm{N}$ bands can be regarded as a function with its cycle of N. Spectral HA decomposition is to express 158 the spectral curve of each soil sample as the sum of a series of superimposed sine and cosine waves 159 composed of some energy characteristic components such as harmonic remainder $\left(\mathrm{A}_{0} / 2\right)$, amplitude $\left(\mathrm{A}_{\mathrm{h}}, \quad 160\right.$ $B_{h}$, and $\left.C_{h}\right)$, and phase $\left(\varphi_{h}\right)$. A group of spectra consisting of $N$ bands is expressed as $V(k)=\left(v_{1}, v_{2}, \ldots, \quad 161\right.$ $\left.\mathrm{v}_{\mathrm{N}}\right)$, and the spectral reflectance of each band is marked as $\mathrm{v}_{\mathrm{k}}(\mathrm{k}=1,2, \ldots, \mathrm{N})$. The harmonic decompo- 162 sition expansion formula of h-times HA is as follows.

$$
\begin{aligned}
V(k) & =\frac{A_{0}}{2}+\sum_{h=1}^{\infty}\left[A_{h} \cos (2 \pi h k / N)+B_{h} \sin (2 \pi h k / N)\right] \\
& =\frac{A_{0}}{2}+\sum_{h=1}^{\infty} C_{h} \sin \left(2 \pi h k / N+\varphi_{h}\right)
\end{aligned}
$$

After the h-th harmonic decomposition of $\mathrm{V}(\mathrm{k})$, the harmonic characteristic components are calcu- 165 lated.

$$
\begin{gathered}
\mathrm{A}_{0} / 2=\frac{1}{\mathrm{~N}} \sum_{\mathrm{k}=1}^{\mathrm{N}} \mathrm{v}_{\mathrm{k}} \\
\mathrm{A}_{\mathrm{h}}=\frac{2}{\mathrm{~N}} \sum_{\mathrm{k}=1}^{\mathrm{N}} \mathrm{v}_{\mathrm{k}} \cos (2 \pi \mathrm{hk} / \mathrm{N}) \\
\mathrm{B}_{\mathrm{h}}=\frac{2}{\mathrm{~N}} \sum_{\mathrm{k}=1}^{\mathrm{N}} \mathrm{v}_{\mathrm{k}} \sin (2 \pi \mathrm{hk} / \mathrm{N}) \\
\mathrm{C}_{\mathrm{h}}=\sqrt{\left(\mathrm{A}_{\mathrm{h}}{ }^{2}+\mathrm{B}_{\mathrm{h}}{ }^{2}\right)} \\
\varphi_{\mathrm{h}}=\tan ^{-1}\left(\mathrm{~A}_{\mathrm{h}} / \mathrm{B}_{\mathrm{h}}\right)
\end{gathered}
$$

Where $\mathrm{h}(\mathrm{h}=1,2,3, \ldots)$ is the number of harmonic decomposition. When $\mathrm{h}=1$, it is the component of the fundamental wave. $A_{0} / 2$ is the harmonic remainder and $C_{h} \sin \left(2 \pi h k / N+\varphi_{h}\right)$ is the harmonic component of $h$ times. $A_{h}, B_{h}, C_{h}$, and $\varphi_{h}$ are the cosine amplitude, sine amplitude, harmonic component amplitude, and the phase of harmonic component of h-th harmonic decomposition, respectively. $\mathrm{A}_{0} / 2$, $C_{h}$, and $\varphi_{h}$ reflect the mean energy of each band, the energy change of different bands, and the band 176 position where the energy appears amplitude. 
The low order harmonics contain the main energy characteristics of the spectra, and the high order

\subsubsection{Principal Component Analysis}

Principal component analysis (PCA) was widely used in data feature extraction, compression, and

\subsection{Back Propagation Model and Accuracy Evaluation}

In spectral analysis, the back propagation (BP) neural network is an important pattern recognition

The prediction accuracy of the models was determined by the parameters of the coefficient of de-

$$
\operatorname{RMSE}=\sqrt{\sum_{\mathrm{i}=1}^{\mathrm{n}}\left(\mathrm{y}_{\mathrm{i}}-\hat{\mathrm{y}}_{\mathrm{i}}\right)^{2} / \mathrm{n}}
$$




$$
\operatorname{MAE}=\frac{1}{\mathrm{n}} \sum_{\mathrm{i}=1}^{\mathrm{n}}\left|\mathrm{y}_{\mathrm{i}}-\hat{\mathrm{y}}_{\mathrm{i}}\right|
$$

where $y_{\mathrm{i}}$ is the measured value, $\hat{y}_{i}$ is the estimated value, $\mathrm{n}$ is the number of samples.

To eliminate spectral noise of the instrument, and process the HFI, the original spectral data were 208 preprocessed by five-point weighted average, FD, WPT, and HA. The workflow is shown in Fig. 2.

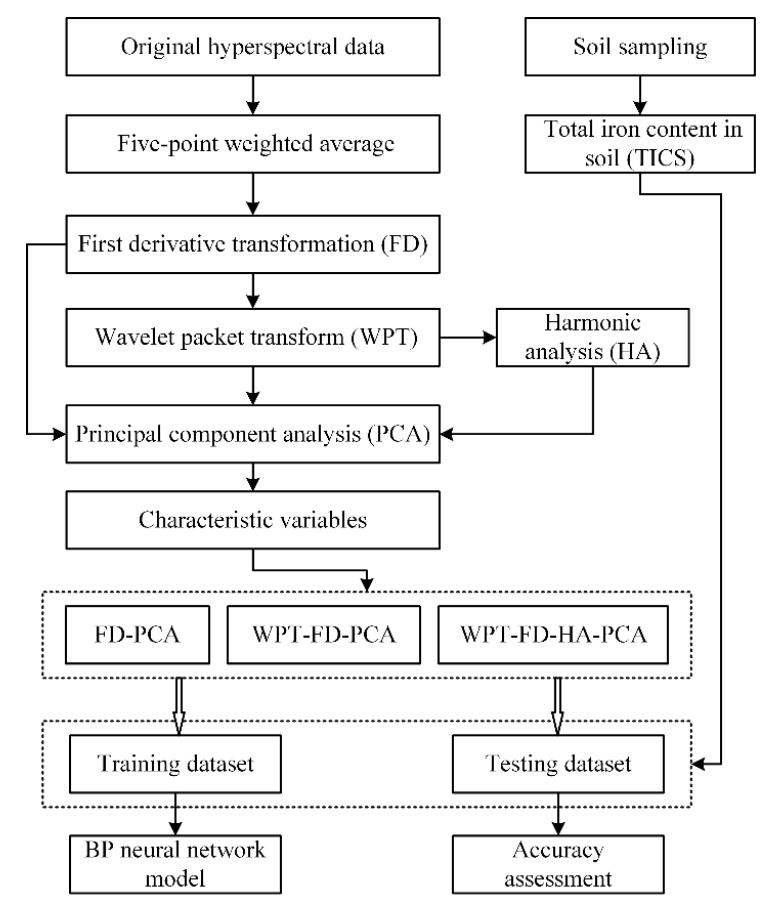

Fig. 2 The flow chart of this study.

The hyperspectral curves of different types of soil were shown in Fig. 3. It can be seen that the waveform of different types of soil and soil with different iron content is generally similar. With the increase of TICS, the reflectance of the whole observation bands decreased gradually, but the overall trend did not change (including the position of the absorption band). It indicated that the spectral reflec- 

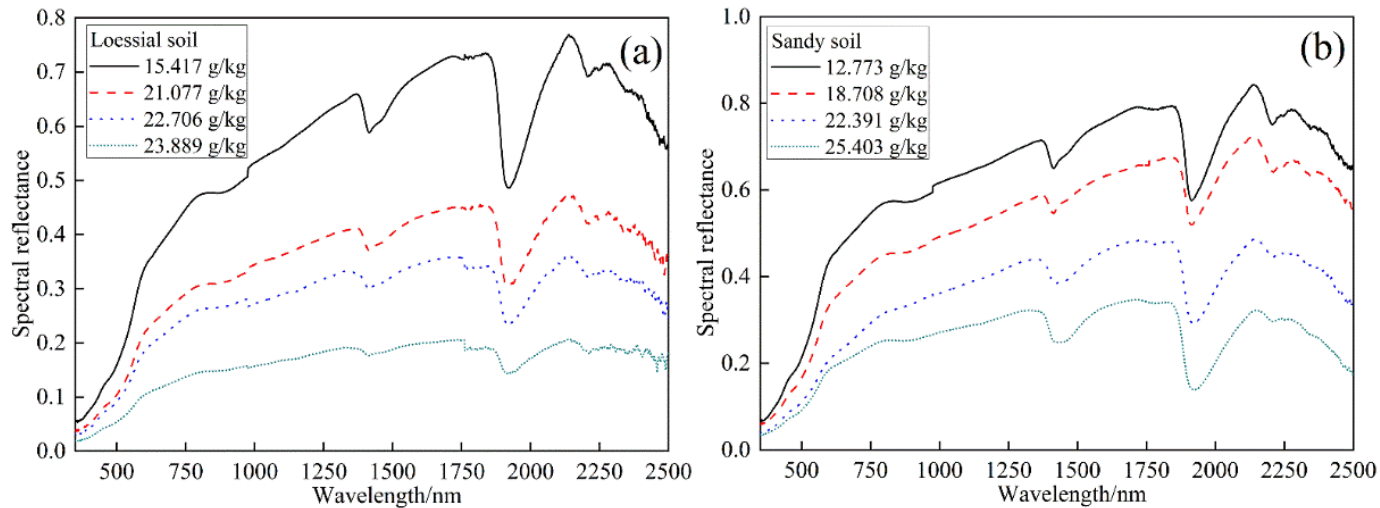

Fig. 3 Primary spectral reflectance of different TICS: (a) loessial soil; (b) sandy soil.

\subsection{Characteristic Bands Selection}

Four kinds of data, including original spectral data (OS), first derivative data (FD), wavelet packet lyze the correlation with the TICS. The results are shown in Fig. 4.

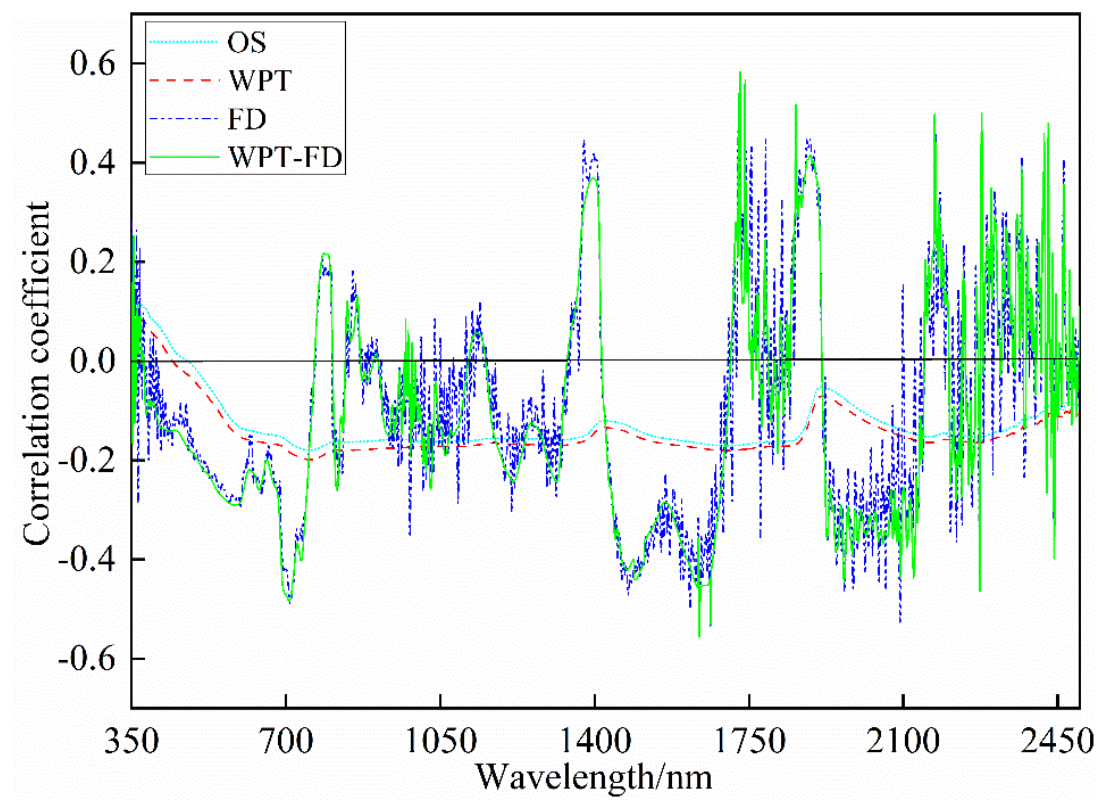

Fig. 4 The correlation between different data and the TICS.

The OS and WPT data were negatively correlated with TICS as a whole (except 350-500 nm) with WPT-FD, and TICS was obviously increased, with the positive and negative values alternated. We cal- 
were selected from FD and WPT-FD data of all soil types. The number of bands remained the same as

\subsection{Harmonic Decomposition}

The WPT-FD data of loessial, sandy and mixed soils were decomposed by using formula (4)-(8) to obtain the characteristic components of harmonic energy spectra $\left(\mathrm{A}_{0} / 2, \mathrm{Ah}, \mathrm{B}_{\mathrm{h}}, \mathrm{C}_{\mathrm{h}}\right.$, and $\left.\varphi_{\mathrm{h}}\right)$. The correla- 237 tion coefficients between the harmonic components and TICS were calculated. The total number of bands 238 of harmonic decomposition was 150 . Considering the periodicity of sine and cosine functions, the times of harmonic decomposition were 150. Fig. 5 shows the correlation coefficients between the characteristic components of different harmonic energy spectra and TICS of loessial soil, sandy soil, and mixed soil.
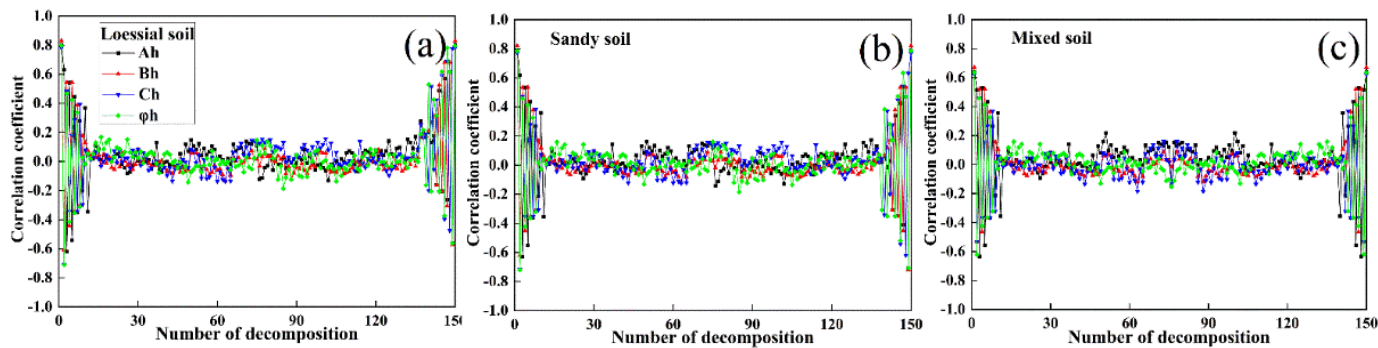

Fig. 5 The correlation between the characteristic components of different harmonic energy spectra and

The results showed that there is a high correlation between harmonic components of first and latter

The spectral parameters and 12 harmonic characteristic parameters were analyzed by PCA to reduce the number of input layer neural networks and improve the network topology and estimation effect. For loessial soil, sandy soil, and mixed soil, the first five components were selected as input variables of BP

Table 2. Eigenvalue and variance contribution rate of different types of soil data. 


\begin{tabular}{|c|c|c|c|c|c|c|c|c|c|c|}
\hline \multirow{2}{*}{ PCA } & \multirow{2}{*}{$\begin{array}{l}\text { Soil } \\
\text { types }\end{array}$} & \multicolumn{3}{|c|}{ Characteristic Value } & \multicolumn{3}{|c|}{$\begin{array}{c}\text { Variance contribution } \\
\qquad(\%) \\
\end{array}$} & \multicolumn{3}{|c|}{$\begin{array}{c}\text { Accumulative contribu- } \\
\text { tion (\%) }\end{array}$} \\
\hline & & FD & WPT-FD & $\begin{array}{l}\text { WPT- } \\
\text { FD-HA }\end{array}$ & FD & $\begin{array}{l}\text { WPT- } \\
\text { FD }\end{array}$ & $\begin{array}{l}\text { WPT- } \\
\text { FD-HA }\end{array}$ & FD & $\begin{array}{l}\text { WPT } \\
\text {-FD }\end{array}$ & $\begin{array}{l}\text { WPT- } \\
\text { FD-HA }\end{array}$ \\
\hline PCA1 & \multirow{5}{*}{$\begin{array}{l}\text { mixed } \\
\text { soil }\end{array}$} & $6.91 \times 10^{-6}$ & $3.62 \times 10^{-5}$ & 1.46 & 74.82 & 84.01 & 90.00 & 74.82 & 84.01 & 90.00 \\
\hline PCA2 & & $9.76 \times 10^{-7}$ & $1.55 \times 10^{-6}$ & 0.18 & 10.56 & 6.02 & 5.00 & 85.38 & 90.03 & 95.00 \\
\hline PCA3 & & $4.36 \times 10^{-7}$ & $4.26 \times 10^{-7}$ & $1.64 \times 10^{-7}$ & 4.72 & 4.11 & 2.00 & 90.10 & 94.14 & 97.00 \\
\hline PCA4 & & $2.72 \times 10^{-7}$ & $1.16 \times 10^{-7}$ & $1.04 \times 10^{-7}$ & 2.95 & 1.30 & 0.75 & 93.04 & 95.42 & 97.75 \\
\hline PCA5 & & $1.26 \times 10^{-7}$ & $4.55 \times 10^{-8}$ & $6.93 \times 10^{-7}$ & 1.36 & 0.12 & 0.23 & 94.41 & 95.56 & 98.99 \\
\hline PCA1 & \multirow{5}{*}{$\begin{array}{l}\text { loessial } \\
\text { soil }\end{array}$} & $3.39 \times 10^{-6}$ & 1.56 & $2.82 \times 10^{-5}$ & 77.00 & 88.81 & 95.88 & 77.00 & 88.71 & 95.88 \\
\hline PCA2 & & $6.21 \times 10^{-7}$ & 0.20 & $8.54 \times 10^{-7}$ & 10.41 & 6.19 & 2.90 & 87.41 & 94.90 & 98.79 \\
\hline PCA3 & & $4.85 \times 10^{-7}$ & 0.07 & $1.28 \times 10^{-7}$ & 6.15 & 2.09 & 0.43 & 93.56 & 96.99 & 99.22 \\
\hline PCA4 & & $1.92 \times 10^{-7}$ & $6.56 \times 10^{-4}$ & $5.79 \times 10^{-8}$ & 3.23 & 0.73 & 0.20 & 96.79 & 97.99 & 99.42 \\
\hline PCA5 & & $1.70 \times 10^{-8}$ & $3.64 \times 10^{-4}$ & $4.56 \times 10^{-8}$ & 0.86 & 0.51 & 0.16 & 97.65 & 98.50 & 99.57 \\
\hline PCA1 & \multirow{5}{*}{$\begin{array}{l}\text { sandy } \\
\text { soil }\end{array}$} & $9.11 \times 10^{-6}$ & $4.71 \times 10^{-5}$ & 1.34 & 86.94 & 89.27 & 90.75 & 86.94 & 89.27 & 90.75 \\
\hline PCA2 & & $6.36 \times 10^{-7}$ & $2.77 \times 10^{-6}$ & 0.15 & 6.07 & 5.26 & 8.75 & 93.01 & 94.53 & 99.50 \\
\hline PCA3 & & $2.12 \times 10^{-7}$ & $1.86 \times 10^{-6}$ & $6.65 \times 10^{-7}$ & 2.02 & 3.51 & 0.26 & 95.03 & 98.04 & 99.76 \\
\hline PCA4 & & $1.45 \times 10^{-7}$ & $7.57 \times 10^{-7}$ & $2.41 \times 10^{-7}$ & 1.39 & 1.43 & 0.10 & 96.41 & 99.48 & 99.86 \\
\hline PCA5 & & $1.01 \times 10^{-8}$ & $8.32 \times 10^{-8}$ & $1.61 \times 10^{-7}$ & 1.05 & 0.16 & 0.05 & 97.46 & 99.64 & 99.90 \\
\hline
\end{tabular}

For three types of soil (mixed soil, loessial soil, and sandy soil), the cumulative variance contribu- 257 tion rates of the first five principal components of WPT-FD data reached $95.56 \%, 98.50 \%$, and 99.64\%, 258 respectively, which fully met the requirements of input variables of BP models (Table 2). The PCA 259 results of WPT-FD data were better than those of FD data in the same band. The cumulative variance 260 contribution rates of the first five principal components of WPT-FD-HA-PCA were 98.98\%, 99.57\%, 261 and $99.90 \%$, respectively, which basically contained the characteristic components of original harmonic 262 energy spectra. Moreover, the results of WPT-FD-HA-PCA were better than those of WPT-FD-PCA, 263 and the effects of data dimensionality reduction were also prior. Based on the above PCA results, three 264 input variables of BP models (FD-PCA, WPT-FD-PCA, and WPT-FD-HA-PCA) were constructed. The 265 PCA results of the WPT-FD-HA-PCA were the best, followed by WPT-FD-PCA, and the FD-PCA was 266 the worst.

The topological structure of the BP model used in this study was $5-3-1$. The number of nodes of 269 the input layer, hidden layer, and output result layer was set as 5, 3, and 1, respectively. The number of 270 network training iterations was 2000, the learning rate was 0.01 , the additional momentum factor was 271 
0.9, and the learning error was 0.001. The above operation was realized based on the software of 272 MATLAB 2018a (MathWorks, Inc., Natick, MA, USA). 273

In the process of BP model establishment, 35 and 20 groups from 51 groups of loessial soil and 33274 groups of sandy soil samples were selected as training samples and the remaining 16 and 13 groups of 275 samples as testing samples. Then we randomly selected 45 groups of samples from 84 groups of mixed 276 soils as the training samples and the remaining 39 groups of sample data as testing samples. BP estima- 277 tion models of the TICS were constructed based on three types of variables (FD-PCA, WPT-FD-PCA, 278 and WPT-FD-HA-PCA). Finally, three inversion models were established for three soil types: FD-PCA- 279 BP, WPT-FD-PCA-BP, and WPT-FD-HA-PCA-BP. The inversion accuracy of different models for three 280 soil types is shown in Table 3. Fitting results between estimated values and measured values of TICS of 281 three types of soil are shown in Figure 6. 282

Table 3. TICS estimation models of different types of soil.

\begin{tabular}{cccc}
\hline Soil types & BP models & $\mathbf{R}^{\mathbf{2}}$ & RMSE \\
\hline \multirow{3}{*}{ loessial soil } & FD-PCA-BP & 0.86 & 1.29 \\
& WPT-FD-PCA-BP & 0.92 & 1.16 \\
& WPT-FD-HA-PCA-BP & 0.95 & 0.68 \\
\multirow{5}{*}{ sandy soil } & FD-PCA-BP & 0.89 & 1.09 \\
& WPT-FD-PCA-BP & 0.93 & 0.88 \\
& WPT-FD-HA-PCA-BP & 0.94 & 0.71 \\
\multirow{2}{*}{ mixed soil } & FD-PCA-BP & 0.71 & 1.83 \\
& WPT-FD-PCA-BP & 0.79 & 1.57 \\
& WPT-FD-HA-PCA-BP & 0.87 & 1.11 \\
\hline
\end{tabular}

For the three types of soil, the estimation result of the WPT-FD-PCA-BP model was evidently better 285 than that of the FD-PCA-BP model (Table 3). The $\mathrm{R}^{2}$ of WPT-FD-PCA-BP models of different soils was 0.79 (mixed soil), 0.92 (loessial soil ), and 0.93 ( sandy soil), and RMSE was 1.57, 1.16, and 0.88, re- 287 spectively. The $\mathrm{R}^{2}$ of the WPT-FD-HA-PCA-BP model was 0.87 (mixed soil), 0.95 (loessial soil), and 288 0.94 (sandy soil), which were higher than those of the WPT-FD-PCA-BP model. Moreover, the inversion 289 accuracy of the WPT-FD-PCA-HA-BP model of a single soil type was higher than that of mixed soil. 290

Fig. 6 showed the comparison between the retrieved and measured values of TICS of different types 291 of soil. The performance of BP models under the conditions of single soil (loessial soil and sandy soil) 292 type was better than that of the mixed soil, which indicated that there existed some differences in spectral 293 characteristics and spectral characteristic bands of various soils. Therefore, the soil property information 294 must be considered in the study of TICS estimation. In terms of the model structure, it can be seen that 295 

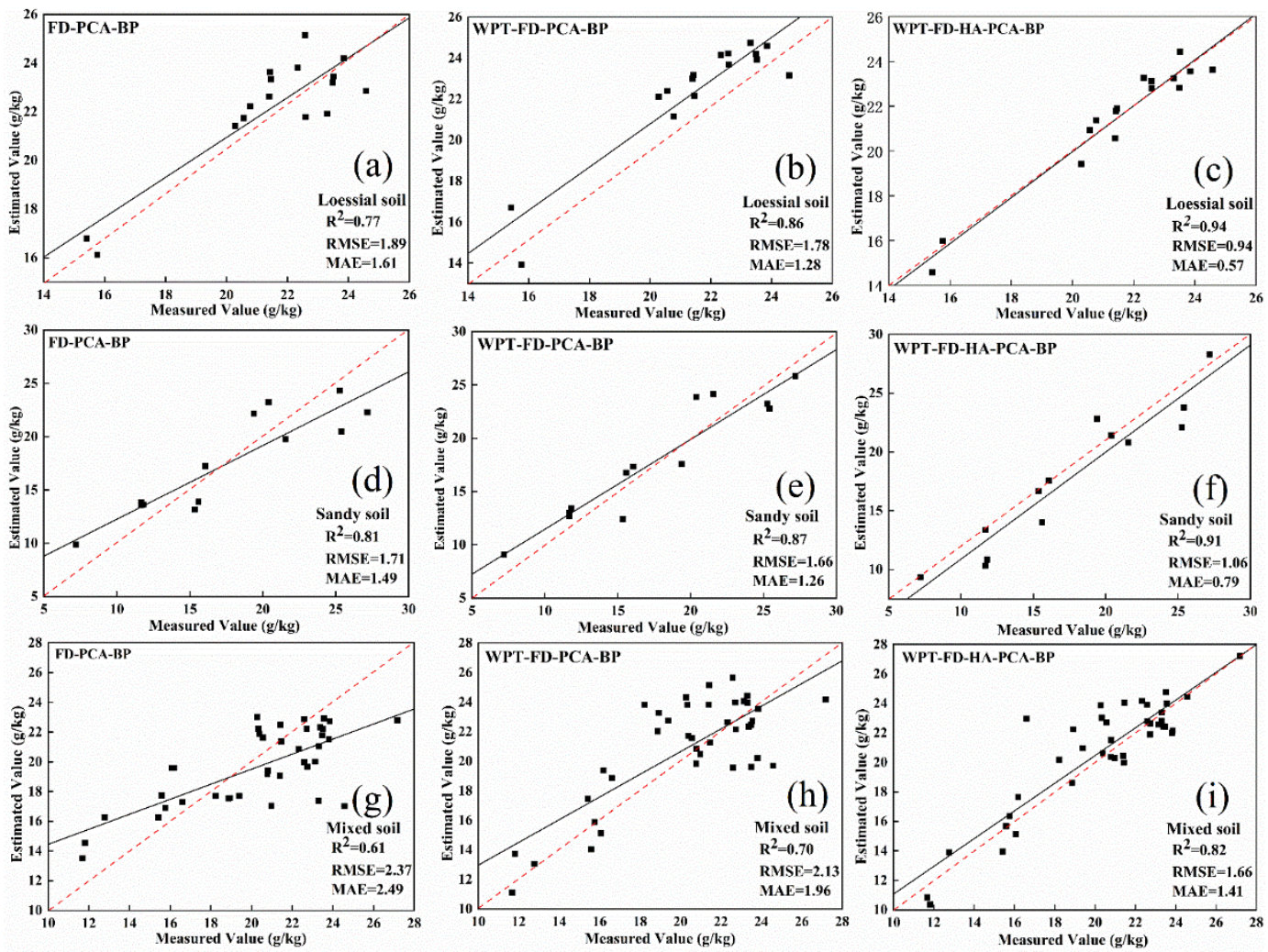

Fig. 6 Validation models of TICS estimation of different types of soil: (a) FD-PCA-BP model of loessial

The comparison of the absolute errors (the difference between the predicted value and the measured 

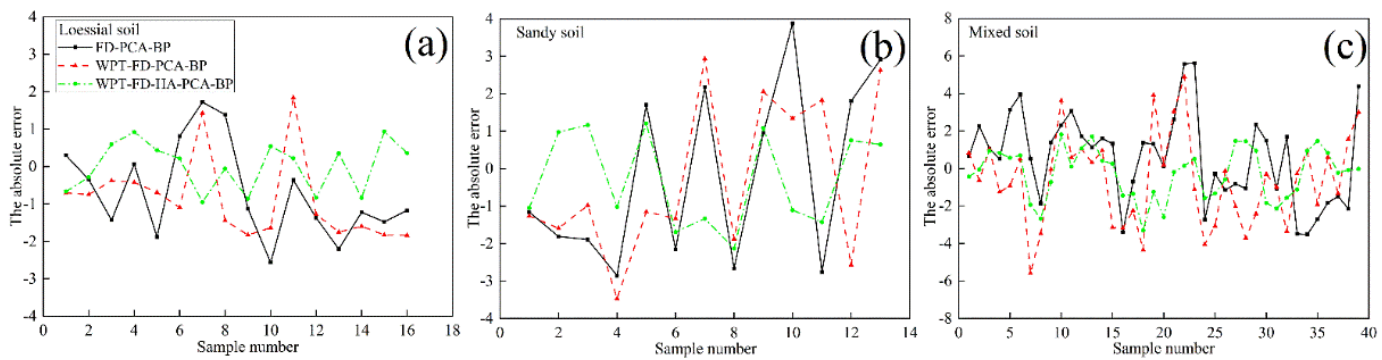

Fig. 7 The absolute error of the TICS estimation of three soil types: (a) loessial soil; (b) sandy soil; (c) mixed soil.

312

\subsection{Superiority Analysis of Harmonic Analysis in Parameters Selection for TICS Estimation}

Soil spectrum is a comprehensive reflection of various soil properties, affecting by the factors of soil organic matter, soil color, soil texture, soil moisture, and mineral composition [28,29]. For the complexity of the composition of soil spectrum, the performance of TICS estimation of characteristic variables obtained by traditional spectral transformation (first and second derivative, reciprocal, logarithm, 320 and continuum removal methods) was often limited [30]. Moreover, compared with the organic matter, 321 water content, and other constant elements, total iron content are obviously different. The main reason is 322 that the low TICS results in a weak spectral signal, and the performance of the inversion models using 323 variables obtained by conventional methods is poor [31].

Through the correlation analysis, it is found that the first derivative spectra tend to have a higher correlation with TICS than the original spectra (Fig. 4). The reason is that the spectral differentiation 326 technology can partially eliminate the effects of atmospheric effects, environmental background, and shadows [32]. The bands with high correlation with TICS are mainly concentrated in the range of 1800$1900 \mathrm{~nm}$, consistent with the characteristic absorption bands of different types of soils.

After WPT reconstruction, the WPT-FD data tend to perform better than the FD data on the corre330 lation with TICS (Fig. 4). Many scholars also used the principle of WPT to denoise the original spectra 331 in the process of spectral data processing for the estimation of soil water content and organic matter [33]. 332 However, given the complex situation of TICS estimation, the correlation between the WPT-FD data 333 with TICS needs to improve.

The HA method proposed in this paper can improve the correlation with TICS by using the harmonic components of harmonic decomposition (Fig. 5). Harmonic decomposition can transform spectral 336 information into signal molecules, which is more stable than spectral parameters and can effectively 337 improve the inversion accuracy of trace elements in the soil. Finally, 12 harmonic components whose $|r| \quad 338$ 
$>0.6$ were determined. Based on the above spectral data preprocessing, we carried out the PCA method 339

to eliminate the correlation between characteristic bands (characteristic parameters). 340

In general, the spectral preprocessing methods used in this paper may be suitable for other studies 341

as well. The different types of these methods were combined and optimized to improve the feasibility of 342

hyperspectral inversion. It provides technical support for the rapid estimation of TICS. According to the 343

characteristics of different physical and chemical soil properties, selecting different methods to improve 344

the accuracy of the model may be an important research direction for quantitative inversion of soil hy- $\quad 345$

$\begin{array}{ll}\text { perspectral in the future. } & 346\end{array}$

4.2. Improvement of Model Accuracy and Universality by Harmonic Analysis 347

In similar studies, the estimation accuracy of the BP model in this paper (Table 3) is higher than the 348 result of Xie et al [34]. They used RBF neural network to estimate the TICS with the $\mathrm{R}^{2}$ of 0.70 . It showed 349 that the HA has a certain contribution to the optimization of BP input variables. For the three types of 350 soils, the characteristic variables from WPT-FD-HA-PCA helped to significantly improve the estimation 351 accuracy of TICS. It was more significant in the mixed soil, the TICS estimation accuracy of the WPT- 352 FD-HA-PCA-BP model increased about $12 \%$, but only $8 \%$ in loessial soil and $4 \%$ in sandy soil (com- 353 pared with the WPT-FD-PCA-BP model), which indicated that the characteristic variables obtained by 354 HA can effectively improve the inversion accuracy of total iron content in mixed soil. Furthermore, the 355 BP model based on HA shows better performance than the model of conventional characteristic bands. 356 Its advantage is that the harmonic parameters were obtained by Fourier transform of the first derivative 357 spectral data reconstructed by wavelet transform. The harmonic parameters replaced the conventional 358 spectral characteristic parameters as the new model input variables to avoid the uncertainty of spectral 359 parameters calculation. It concluded that the HA plays a decisive and stable role in the process of TICS 360 estimation.

The BP estimation model based on HA can not only adapt to the inversion of total iron content in a 362 single soil type but also has good performance for mixed soil $\left(\mathrm{R}^{2}=0.87, \mathrm{RMSE}=1.11\right)$, which reflects 363 the effectiveness and feasibility of the TICS estimation using HA. For loessial soil and sandy soil, the 364 WPT-FD-PCA-HA-BP model shows higher accuracy than the other two models (FD-PCA-BP and WPT- 365 FD-PCA-BP), indicating that the WPT-FD-HA-PCA-BP model has better adaptability for single soil 366 type of total iron content inversion (Table 3). For mixed soil, the inversion and validation accuracy of 367 the WPT-FD-PCA-HA-BP model is much higher than that of the WPT-FD-PCA-BP model (Table 3 and 368 
Fig. 6), which indicates that the harmonic parameters obtained by harmonic decomposition can effec-

tively improve the TICS estimation, and the inversion variables can be well applied to the soil with rich

types. The relationship between TICS and spectral reflectance is not a simple linear relationship [35], 371

and a large number of studies have proved that the BP model is good in dealing with nonlinear problems 372

[36]. Combined with the results of this experiment, the feasibility and superiority of the BP model in 373

$\begin{array}{ll}\text { retrieving TICS were verified again. } & 374\end{array}$

As shown in Fig. 6, the WPT-FD-PCA-HA-BP validation models show the best performance (the 375

highest $\mathrm{R}^{2}$, the lowest RMSE and MAE of different types of soil). Compared with the results of TICS 376

estimation by a large number of scholars, the inversion accuracy in this paper is obviously improved. 377

The results show that the new factors proposed in this present have some improvements compared with 378

the traditional inversion parameters, which mainly act on the following aspects: (1) the spectral denoising 379

effect of WPT is effective, which contributes to the optimization of BP inversion factors. (2) among the 380

TICS estimation models of different types of soil, HA-based models were the best. This highlights the 381

determinacy and stability of HA in the inversion process of total iron content. (3) the TICS estimation 382

models based on HA can be well adapted to single soil and mixed soil types. (4) there is no single linear 383

relationship between TICS and spectral reflectance, which verifies the feasibility and superiority of the 384

BP model in the TICS estimation.

\section{Conclusions}

In this study, we proposed a kind of characteristic variable to estimate TICS using harmonic de- 387 composition parameters. It is observed that the traditional spectral parameters are unstable and subject 388 to noise in the TICS estimation. The HA transforms the spectra data from spectral-domain to frequency 389 domain, which avoids the uncertainty and reduces the error of spectral parameter calculation. The BP 390 inversion models of TICS based on HA not only has high inversion accuracy for a single soil type but 391 also can be applied to mixed soil well, avoiding the limitations and singleness of experimental results. 392 The WPT-FD-HA-PCA-BP model which is suitable for different soil types is a good inversion method 393 of TICS and has certain universality. There is an important reference value for determining the best 394 $\begin{array}{ll}\text { characteristic variable for the TICS estimation. } & 395\end{array}$

Ethics approval and consent to participate 
The authors would like to thank the editors and the anonymous reviewers for their valuable comments and sugges-

\section{References}

1. Colombo, C.; Palumbo, G.; He, J.Z.; Pinton, R.; Cesco, S. Review on iron availability in soil: interaction of 
spectrometry after extraction induced by solid-oil-water emulsion breaking. Food Chemistry 2021, 345, 424 128766-128766, doi:10.1016/j.foodchem.2020.128766.

5. Bener, M.; Apak, R. Ferric-o-phenanthroline adsorbed on a Nafion membrane: A novel optical sensor for antioxidant capacity measurement of food extracts. Sensors and Actuators B-Chemical 2017, 247, 155-162, 427 doi:10.1016/j.snb.2017.03.017.

6. Abdel-Rahman, E.M.; Mutanga, O.; Odindi, J.; Adam, E.; Odindo, A.; Ismail, R. Estimating Swiss chard foliar

macro-and micronutrient concentrations under different irrigation water sources using ground-based 430 hyperspectral data and four partial least squares (PLS)-based (PLS1, PLS2, SPLS1, and SPLS2) regression 431 algorithms. Computers and Electronics in Agriculture 2017, 132, 21-33, doi:10.1016/j.compag.2016.11.008. 
12. Cheng, H.; Wang, J.; Du, Y.; Zhai, T.; Fang, Y.; Li, Z. Exploring the potential of canopy reflectance spectra density. Spectrochimica Acta Part a-Molecular and Biomolecular Spectroscopy 2020, 240, 452 doi:10.1016/j.saa.2020.118566. parameters of the continuum removal method. European Journal of Remote Sensing 2019, 52, 155-168, 456 doi:10.1080/22797254.2019.1572460.

15. Guo, Y.; Guo, Z.X.; Liu, J.; Yuan, Y.Z.; Sun, H.; Chai, M.; Bi, R.T. Hyperspectral inversion of paddy soil iron 458 oxide in typical subtropical area with Pearl River Delta, China as illustration. The journal of applied ecology 
17. Gu, X.; Wang, Y.; Sun, Q.; Yang, G.; Zhang, C. Hyperspectral inversion of soil organic matter content in cultivated land based on wavelet transform. Computers and Electronics in Agriculture 2019, 167, 465 doi:10.1016/j.compag.2019.105053.

18. Al-Momani, S.; Mir, H.; Al-Nashash, H.; Al-Kaylani, M. Machine Learning Assisted Multi-Functional 467 Graphene-Based Harmonic Sensors. Ieee Sensors Journal 2021, 21, $8375-8383,468$ doi:10.1109/jsen.2020.3047666.

19. Deng, Y.; Zhou, X.; Shen, J.; Xiao, G.; Hong, H.; Lin, H.; Wu, F.; Liao, B.-Q. New methods based on back 470 propagation (BP) and radial basis function (RBF) artificial neural networks (ANNs) for predicting the 471 occurrence of haloketones in tap water. The Science of the total environment 2021, 772, 145534-145534, 472 doi:10.1016/j.scitotenv.2021.145534.

20. Yang, J.; Du, L.; Gong, W.; Shi, S.; Sun, J.; Chen, B. Analyzing the performance of the first-derivative 474 fluorescence spectrum for estimating leaf nitrogen concentration. Optics Express 2019, 27, 3978-3990, doi:10.1364/oe.27.003978.

21. Zhou, R.; Bao, W.; Li, N.; Huang, X.; Yu, D. Mechanical equipment fault diagnosis based on redundant second 477 generation wavelet packet transform. Digital Signal Processing 2010, 20, 276-288, 478 doi:10.1016/j.dsp.2009.04.005.

22. Evagorou, D.; Kyprianou, A.; Lewin, P.L.; Stavrou, A.; Efthymiou, V.; Metaxas, A.C.; Georghiou, G.E. 480 Feature extraction of partial discharge signals using the wavelet packet transform and classification with a 481 probabilistic neural network. Iet Science Measurement \& Technology 2010, 4, 177-192, doi:10.1049/iet- 482 smt.2009.0023. 
23. Wu Dai, H.; Fan Wen, J.; Cui, Y.-k.; Yan Bin, Y.; Xu Xi, R. Review of Monitoring Soil Water Content Using

Hyperspectral Remote Sensing. Spectroscopy and Spectral Analysis 2010, 30, 3067-3071, 485 doi:10.3964/j.issn.1000-0593(2010)11-3067-05.

24. Yang, K.; Zhang, T.; Wang, L.; Qian, X.; Liu, S.; Wang, L. A new algorithm on hyperspectral image fusion 487 based on the harmonic analysis. Journal of China University of Mining \& Technology 2014, 43, 547-553.

25. Sun, W.; Du, Q. Graph-Regularized Fast and Robust Principal Component Analysis for Hyperspectral Band 489 Selection. Ieee Transactions on Geoscience and Remote Sensing 2018, 56, 3185-3195, 490 doi:10.1109/tgrs.2018.2794443.

26. Nomikos, P.; Macgregor, J.F. MONITORING BATCH PROCESSES USING MULTIWAY PRINCIPAL 492 COMPONENT ANALYSIS. Aiche Journal 1994, 40, 1361-1375, doi:10.1002/aic.690400809.

27. Han, J.-X.; Ma, M.-Y.; Wang, K. Product modeling design based on genetic algorithm and BP neural network. 
31. Zhang, X.; Zhang, F.; Kung, H.-t.; Shi, P.; Yushanjiang, A.; Zhu, S. Estimation of the Fe and Cu Contents of

32. Bagtash, M.; Zolgharnein, J. Removal of brilliant green and malachite green from aqueous solution by a viable 


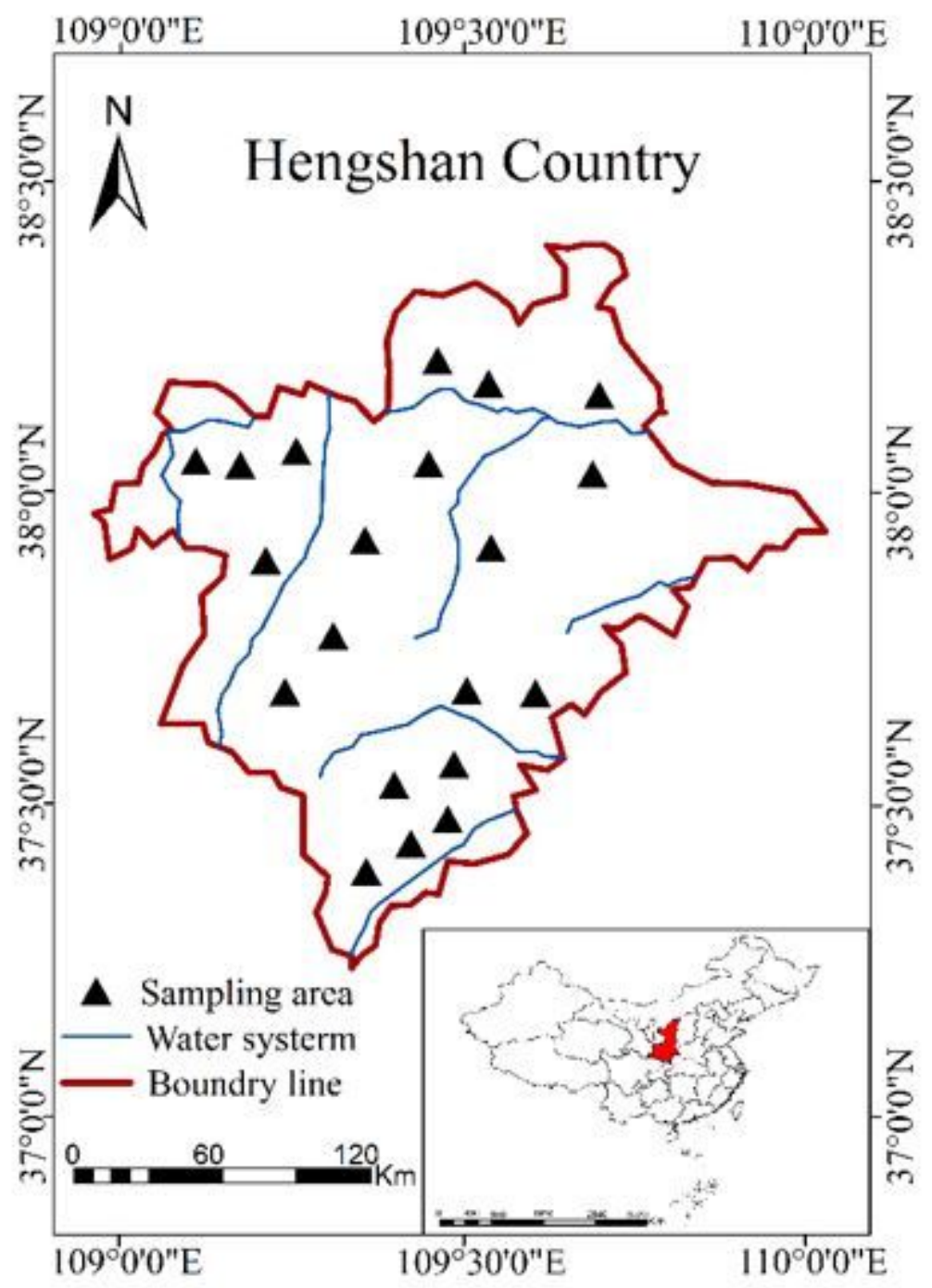

Figure 1

Study area location and sampling points distribution. Note: The designations employed and the presentation of the material on this map do not imply the expression of any opinion whatsoever on the part of Research Square concerning the legal status of any country, territory, city or area or of its authorities, or concerning the delimitation of its frontiers or boundaries. This map has been provided by the authors. 


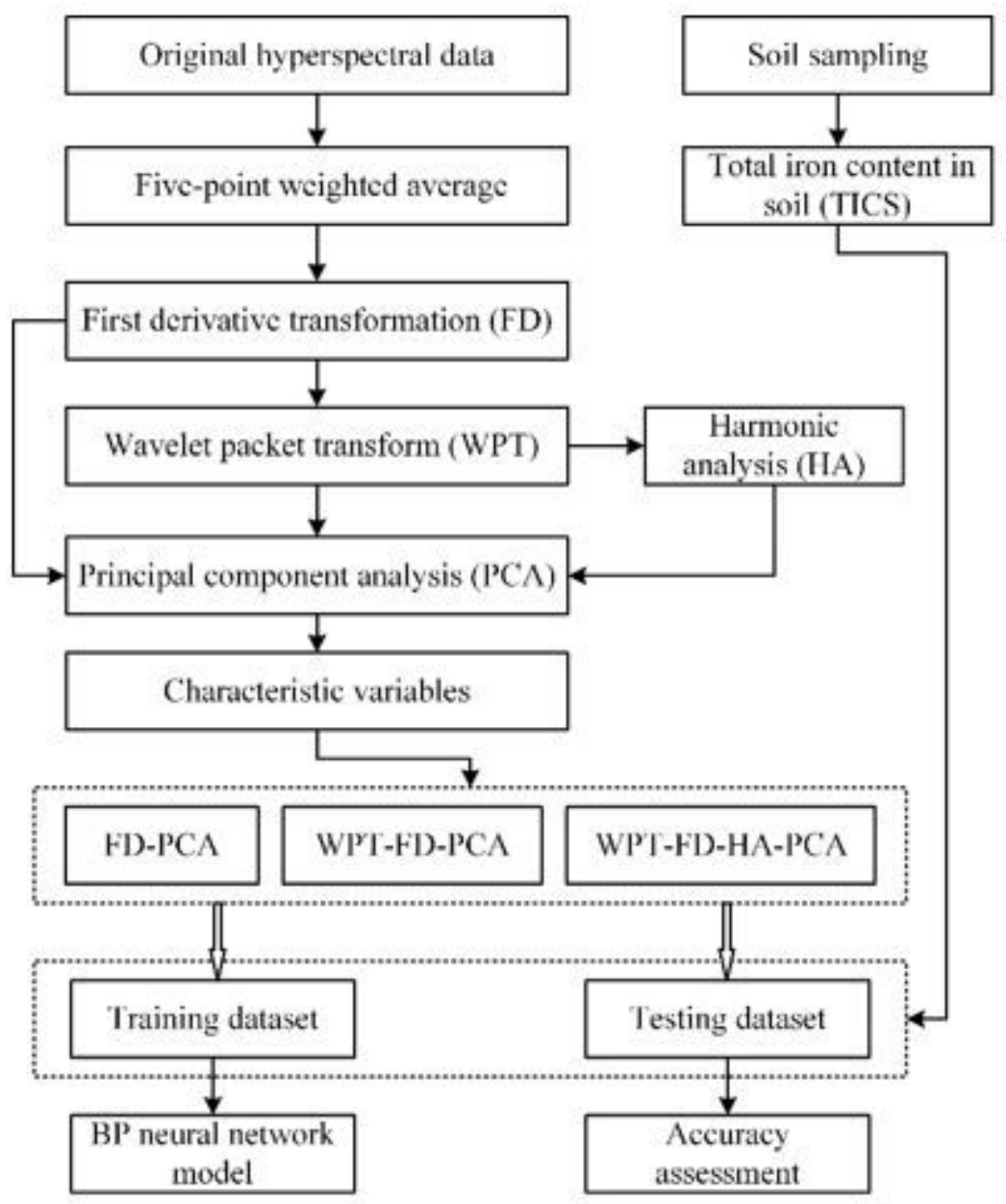

Figure 2

The flow chart of this study.
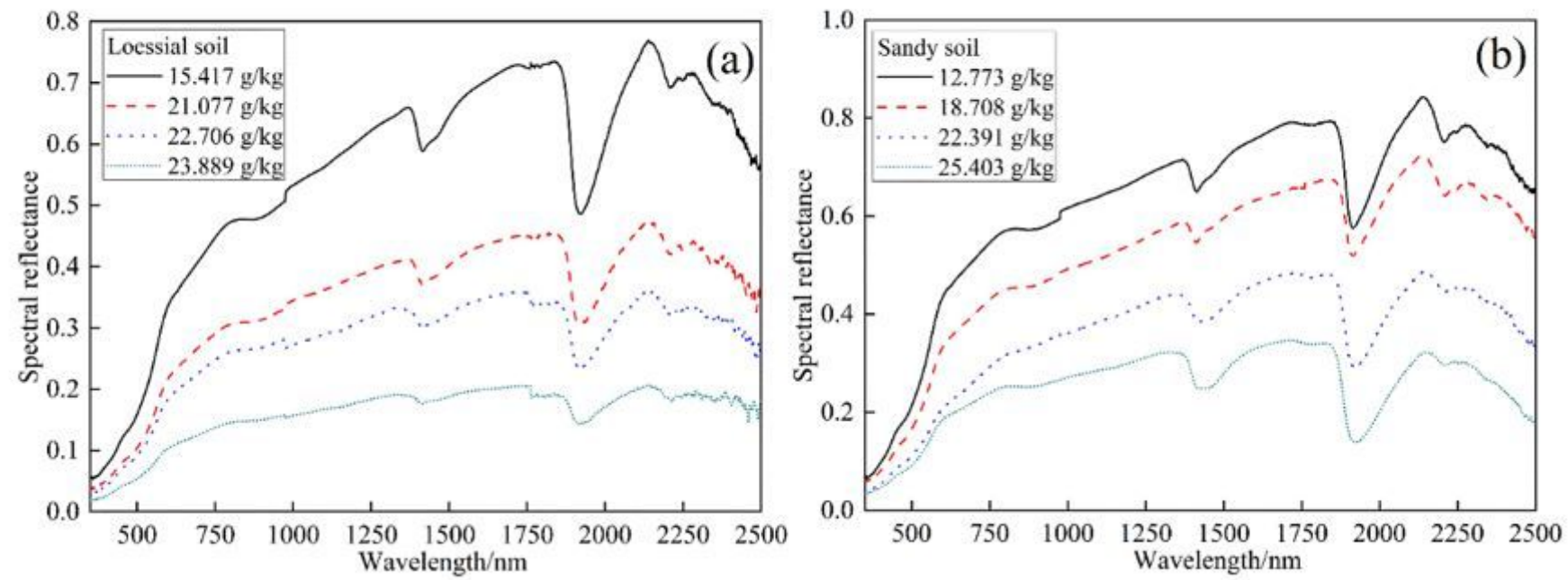

Figure 3 
Primary spectral reflectance of different TICS: (a) loessial soil; (b) sandy soil.

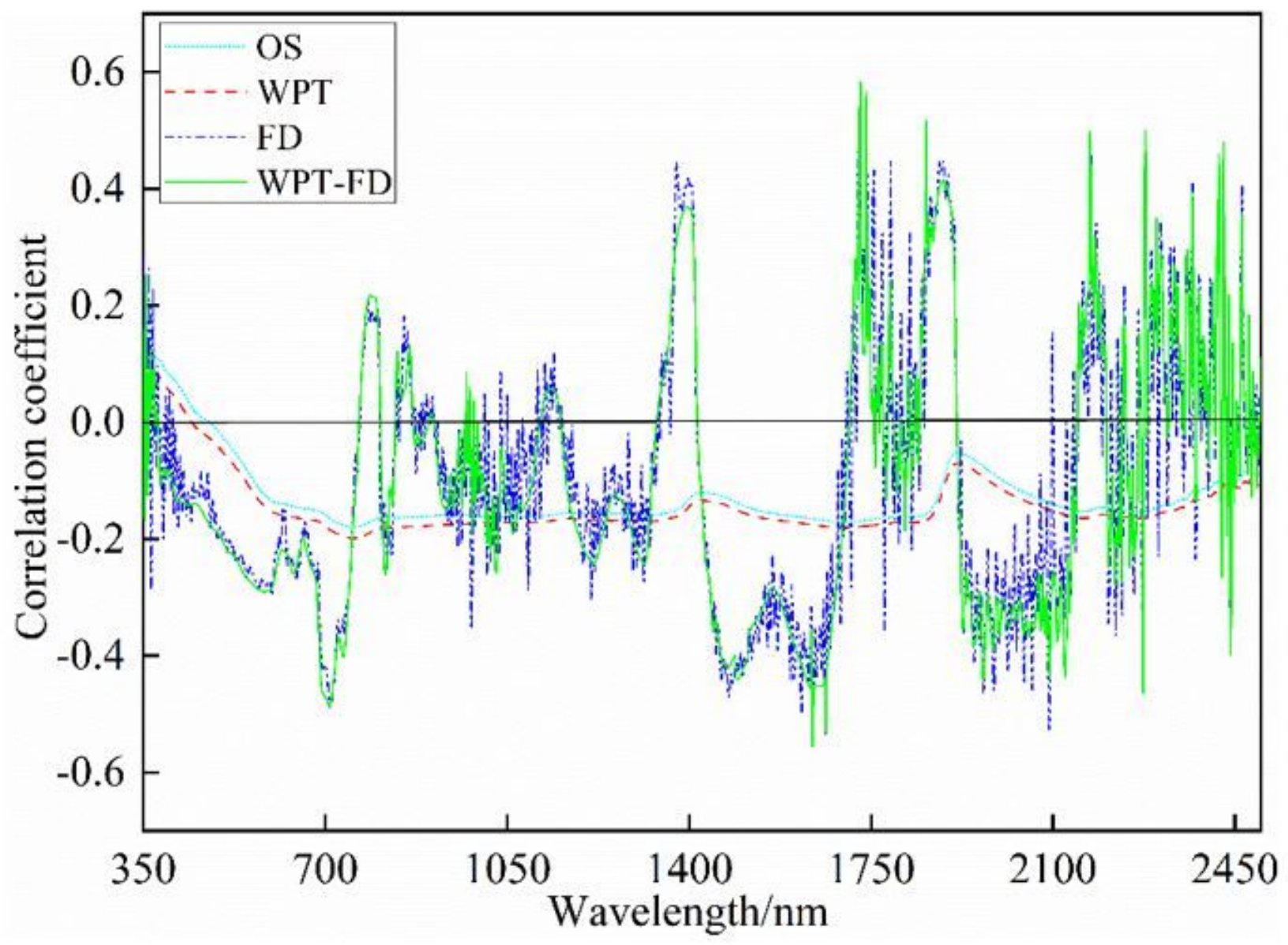

Figure 4

The correlation between different data and the TICS
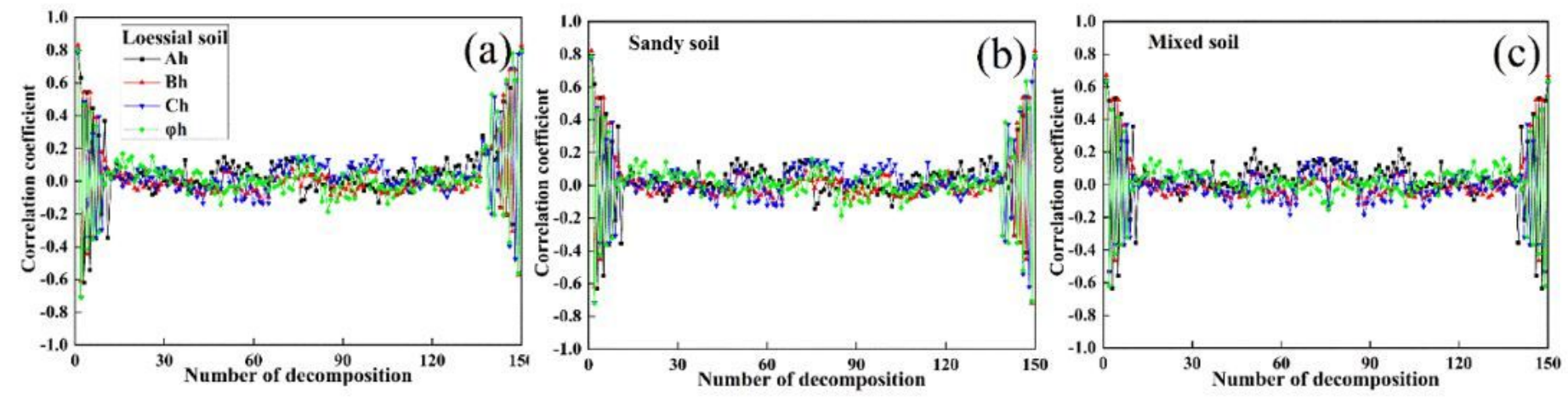

Figure 5

The correlation between the characteristic components of different harmonic energy spectra and TICS:

(a) mixed soil; (b) loessial soil; (c) sandy soil. 

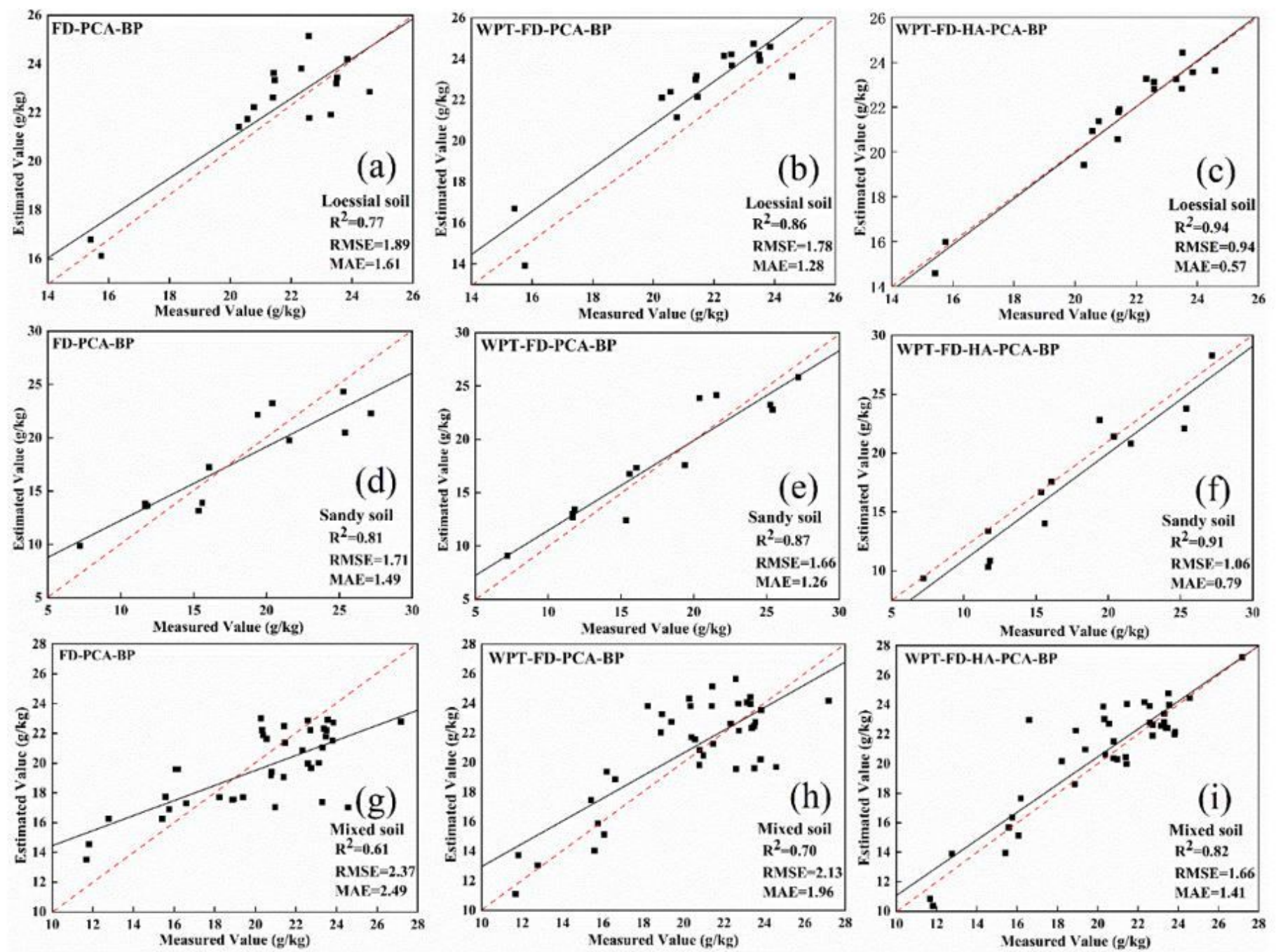

Figure 6

Validation models of TICS estimation of different types of soil: (a) FD-PCA-BP model of loessial soil; (b) WPT-FD-PCA-BP model of loessial soil; (c) WPT-FD-HA-PCA-BP model of loessial soil; (d) FD-PCA-BP model of sandy soil; (e) WPT-FD-PCA-BP model of sandy soil; (f) WPT-FD-HA-PCA-BP model of sandy soil; (g) FD-PCA-BP model of mixed soil; (h) WPT-FD-PCA-BP model of mixed soil; (i) WPT-FD-HA-PCA-BP model of mixed soil.
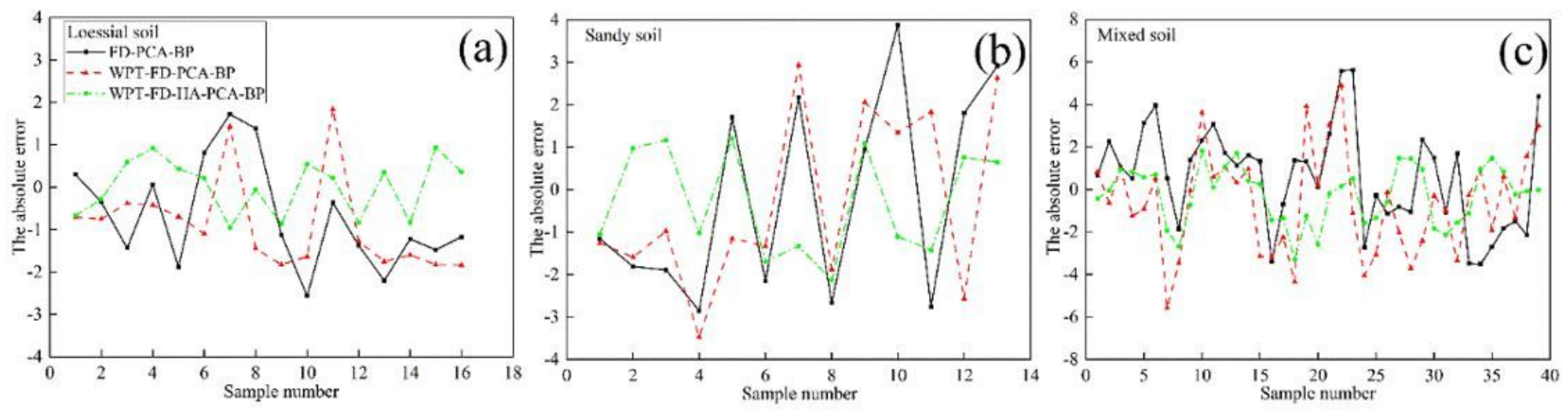


\section{Figure 7}

The absolute error of the TICS estimation of three soil types: (a) loessial soil; (b) sandy soil; (c) mixed soil. 